\title{
Antibiotic Susceptibility Patterns and Extended Spectrum Beta-Lactamase (ESBL) production in Enterobactericeae Isolated from Stool Samples of HIV and AIDS Patients in Ibadan, Nigeria
}

Falodun Olutayo Israel', Ajayi Olayemi' ${ }^{1}$, Ademola Ebenezer Adewuyi2, Bakarey Adeleye Solomon ${ }^{3}$

${ }^{1}$ Department of Microbiology, Faculty of Science, University of Ibadan, Ibadan, Nigeria

2Department of Biological Science and Biotechnology, Caleb University, Imota, Lagos

${ }^{3}$ Institute for Advanced Medical Research and Training, College of Medicine, University of Ibadan, Ibadan, Nigeria

\begin{abstract}
Background and Objectives: Abuse and indiscriminate use of antibiotics, prolong hospital admission, travel history, organ transplants, immunocompromised conditions and age are parts of the factors that contribute to development of antibiotic resistance and intestinal carriage of Extended Spectrum Beta-Lactamases (ESBL) Enterobacteriaceae. These bacteria affect the course and outcome of an infection and continue to pose a challenge to infection management worldwide. This study was carried out to determine the antimicrobial susceptibility patterns and prevalence of ESBL-producing Enterobacteriaceae isolated from stool samples of HIV and AIDS patients in Ibadan, Nigeria.
\end{abstract}

Materials and Methods: One hundred stool samples were collected from consenting HIV and AIDS patients accessing care in Antiretroviral (ARV) Clinic in a secondary and a tertiary health care facility in Ibadan, Nigeria. Gram-negative bacteria were isolated and identified using conventional methods. Antimicrobial susceptibility test was carried out using the Kirby Bauer disc diffusion technique. Phenotypic detection of ESBL-producing isolates was carried out using Double Disc Synergy Test (DDST).

Results: A total of 240 Gram-negative bacteria were isolated comprising 100 (41.6\%) Escherichia coli, 33(13.8\%) Klebsiella pneumonia, 27(11.3\%) Serratia marcescens, 20(8.3\%) Salmonella enterica, 9(3.8\%) Proteus vulgaris, 13(5.4\%) Proteus mirabilis, 21(8.8\%) Citrobacter freundii and 17(7.1\%) Enterobacter aerogenes. Out these, 56 (23.3\%) were ESBL-producers; comprising 23(41.0\%) Escherichia coli, 9(16.0\%) Klebsiella pneumonia, 6(10.7\%) Serratia marcescens, 5(8.9\%) Salmonella enterica, 3(5.3\%) Proteus vulgaris, 5(8.9\%) Proteus mirabilis, 2(3.6\%) Citrobacter freundii and 3(5.4\%) Enterobacter aerogenes. Among the ESBL producers, $45(80.3 \%)$ and $38(67.8 \%)$ showed resistance to trimethoprim/sulfamethoxazole and aztreonam while 3 (3.5\%) showed resistance to ertapenem. Also, 96.4\% (54/56) of the ESBL producers were multidrug resistant.

Conclusion: This study showed that HIV and AIDS patients are reservoirs of ESBL-producing Enterobacteriaceae through faecal carriage, presenting them as likely source of dissemination of ESBL producer in community and hospital settings.

Keywords: Antibiotic resistance, Enterobacteriaceae, Extended Spectrum Beta-Lactamase 


\section{INTRODUCTION}

Over the years, antibiotics have been used to combat infections and to save lives; however microorganisms have successfully evolved with various mechanisms of resisting the effects of antibiotics, thus rendering them inactive [1]. One of these is the synthesis of Beta-Lactamase enzymes, which hydrolyze the Beta-Lactam ring structures of antibiotics, thereby rendering them inactive [2]. This resistance mechanism is currently on the increase in Gram-negative bacteria in both hospitalized and nonhospitalized patients. The prevalence of Betalactamases producing bacteria varies from one geographical location to another, but it is usually directly proportional to the use, and misuse of antibiotics concerned [3]. The $\beta$-Lactams, being most frequently prescribed and most commonly used antibiotics for treatment of bacterial infections due to their broad spectra and minimal side effects; the risk factors of acquiring ESBL producing Enterobacteriaceae in this case due to prolonged intake of the antibiotics is a possibility $[4,5,6]$.

Global epidemiology of ESBLs has been termed to be complicated, especially considering the wider geographical area, the country, the hospital, the community, and the host (either a patient or healthy carrier), as well as various reservoirs, including the environment and animals [6].

Faecal carriage of ESBL producing Enterobacteriaceae in hospital and community settings have been reported from studies carried out in Zimbabwe (13.7\%) [7], Chad (44.5\%) [8, Turkey (34.5\%) [9], Japan (6.4\%) [10], Peru (64.2\%)[11] and Nigeria (17.3\%) [12].

Escherichia coli and Klebsiella species are the most common producers of ESBL. Other Gramnegative bacteria species from which ESBL production has been reportedwhich include Citrobacter, Proteus, Serratia, Salmonella,
Acinetobacter, Kluyvera and specifically members of the genus Enterobacteriaceae. It has been discovered that travellers to countries like Egypt and India, where very high rates of ESBL are present have been noted to become readily colonized asymptomatically with CTX-Mproducing ESBL strains[13]. While ESBLproducing E. coli and other Enterobacteriaceae, particularly those producing CTX-M, have spread rapidly among humans, there are also evidences of spread among pets, and farm animals; products of the food chain, and sewage [14].

In Africa, ESBLs-producing bacteria have been widespread in hospitals, and are increasing in community settings where they cause variety of infections [15]. The main reservoir of ESBLproducing Enterobacteriaceaein hospital settings is intestinal carriage. The gut colonization of inpatients in long term care units has been identified as a high risk for developing self and cross infections due to ESBL-producers; so also history of extended antibiotic courses. Other factors include: prolonged hospital admission, travel history, and host factors such as transplant, neuropenic condition, immunosuppression, and age $[16,17,18]$.

Several studies in Nigeria have shown that abuse, and indiscriminate use of antibiotics by people practicing self-medication, are partly responsible for the high prevalence of multidrug resistance, and ESBL-producing bacteria, in both community; and hospital acquired infections [19, 20]. Similarly, the empirical use of antibiotics as prophylactics against opportunistic infection among people living with HIV and AIDS can stimulate the development of resistance and make them potential reservoir of ESBL producing bacteria. The aim of this study was to determine the antimicrobial susceptibility patterns and prevalence of ESBL-producing Enterobacteriaceae isolated from stool samples of HIV and AIDS patients in Ibadan, Nigeria. 


\section{MATERIALS AND METHODS}

Ethical Approval: The ethical approval for this study was obtained from the University of Ibadan/University College Hospital (UI/UCH) Ethical Committee (Approval number -UI/EC/17/0072). Consent of the patients was sought before the collection of the samples; and all the samples were assigned laboratory codes so as to prevent the disclosure of the patients' identities.

Study population: This study was carried out among the HIV and AIDS patients attending Antiretroviral (ARV) Clinic of the APIN-PEPFAR University College Hospital and Adeoyo Maternity Hospital in Ibadan, Nigeria.

Sample Collection: Stool samples were aseptically collected from consenting HIV and AIDS patients into sterile universal sample bottles between February and March, 2017 with the assistance of the medical personnel. The samples were stored and transported in ice packs to the Pathogenic Laboratory of the Department of Microbiology, University of Ibadan, for immediate processing. The age and sex of the patients were recorded.

\section{Isolation and Identification of Gram-Negative}

Bacteria: The stool samples were serially diluted and plated out on Nutrient Agar, MacConkey (MAC) Agar and Eosin Methylene Blue (EMB) agar using standard pour plate technique. The plates were incubated at $37^{\circ} \mathrm{C}$ for 48 hours. The Total Heterotrophic Bacterial Count (THBC) and Total Coliform Count (TCC) were determined using Nutrient Agar and MacConkey agar, respectively. Colonies on EMB and MAC agar plates were sub-cultured until pure isolates were obtained. Identification of the isolates was carried out using their colonial morphology, microscopic and standard biochemical tests.
Antimicrobial Susceptibility Test of the Isolates: The antibiotic susceptibility test of the isolates was carried out using the standard disc diffusion technique based on recommendation of Clinical Laboratory Standards Institute [21] using Mueller-Hinton agar. The antibiotics used were obtained from Oxoid (UK) and include: cefotaxime $(30 \mu \mathrm{g}), \quad$ ceftazidime $(30 \mu \mathrm{g})$, cefpodoxime $(10 \mu \mathrm{g})$, aztreonam $(10 \mu \mathrm{g})$, gentamicin $\quad(10 \mu \mathrm{g}), \quad$ ciprofloxacin $(10 \mu \mathrm{g})$, trimethoprim/Sulfamethoxazole $(25 \mu \mathrm{g})$, chloramphenicol $(30 \mu \mathrm{g})$, ertapenem $(10 \mu \mathrm{g})$ and amoxicillin/clavulanate $(20 / 10 \mu \mathrm{g})$. Colonies of 18-24 hours old culture were suspended in a tube containing sterile normal saline and the turbidity adjusted to 0.5 McFarland standards. Using a sterile swab stick, the plates were inoculated by swabbing and incubated at $37^{\circ} \mathrm{C}$ for $18-24$ hours after the antibiotics discs were carefully placed on the culture plates. The zones of inhibition were measured, recorded and interpreted using CLSI standards [21].

\section{Screening and Detection of ESBL production} by the Isolates: Isolates that showed resistance to at least one of cefotaxime $(30 \mu \mathrm{g})$, ceftazidime $(30 \mu \mathrm{g})$, cefpodoxime $(10 \mu \mathrm{g})$, and aztreonam $(10 \mu \mathrm{g})$ were selected for ESBL detection and was carried out using double disc synergy test. The standardized culture suspension of the suspected ESBL producers were inoculated on Mueller Hinton agar plates by uniformly swabbing the entire surface of the agar plates. Discs of ceftazidime (30mg), cefpodoxime (10mg) and cefotaxime $(30 \mathrm{mg})$ were placed around augmentin $(20 \mu \mathrm{g}$ amoxicillin $+10 \mu \mathrm{g}$ clavulanate $)$ disc at a distance of $20 \mathrm{~mm}$ (center to center). The plates were incubated at $37^{\circ} \mathrm{C}$ for $16-18$ hours and isolates that showed zones of inhibition around any cephalosporin discs with a clear cut increase towards the augmentin were considered to be ESBL producers. Extended Spectrum Beta-Lactamase positive Escherichia 
coli (ATCC 25922) strain was used as positive control.

Statistical Analysis: This was carried out using SPSS software, version 16 (SPSS, Chicago, IL). The significance level was determined using chisquare test to determining association between categorical variables where appropriate. A pvalue $<0.05$ was considered statistically significant.

\section{RESULTS}

One hundred stool samples were collected from the consenting patients comprising 32 and 68 male and female patients, respectively. The patient's age ranged between 16 and 83 years. $\mathrm{cfu} / \mathrm{mL}$ ) was from the age range 56-65 years (Table 1).

A total of 240 Gram-negative bacteria belonging to seven genera were isolated from the stool samples of the HIV and AIDS patients. The frequency of occurrence of the isolates showed that Escherichia coli has the highest of $41.7 \%$ $(100 / 240)$, followed by Klebsiella pneumonia, Serratia marcescens, Citrobacter freundii, Salmonella enterica, Enterobacter aerogens and Proteus mirabilis with $13.8 \%$ (33/240), 11.3\% (27/240), 8.8\% (21/240), 8.3\% (20/240),7.1\% $(17 / 240)$ and $5.4 \%$ (13/240), respectively; while the least prevalent isolate was $P$. vulgaris with $3.8 \% \quad(9 / 240) \quad$ (Table 2). The antibiotics susceptibility patterns of the isolates showed that

Table 1: Total Heterotrophic Bacterial Count (THBC) and Total Coliform Count (TCC) of the Stool Samples from HIV and AIDS Patients based on their age group

\begin{tabular}{|c|c|c|c|c|c|}
\hline \multirow{2}{*}{$\begin{array}{l}\text { Age Range } \\
\text { (years) }\end{array}$} & \multicolumn{2}{|c|}{ Gender } & \multirow[t]{2}{*}{ Total number } & \multirow{2}{*}{$\begin{array}{l}\text { TBC }\left(\times 10^{2}\right) \\
(\text { Mean } \pm \text { SD })\end{array}$} & \multirow{2}{*}{$\begin{array}{l}\text { TCC }\left(\times 10^{2}\right) \\
(\text { Mean } \pm \text { SD })\end{array}$} \\
\hline & Male & Female & & & \\
\hline $16-25$ & 3 & 1 & 4 & $39.5 \pm 14.0$ & $13.2 \pm 5.7$ \\
\hline $26-35$ & 5 & 17 & 22 & $34.8 \pm 19.2$ & $11.6 \pm 4.4$ \\
\hline $36-45$ & 8 & 21 & 29 & $33.9 \pm 14.3$ & $11.3 \pm 4.0$ \\
\hline 46-55 & 7 & 9 & 16 & $35.7 \pm 11.7$ & $11.9 \pm 4.6$ \\
\hline $56-65$ & 3 & 7 & 10 & $31.0 \pm 18.8$ & $10.3 \pm 2.8$ \\
\hline $66-75$ & 4 & 2 & 6 & $39.2 \pm 14.5$ & $13.1 \pm 5.3$ \\
\hline $76-83$ & 0 & 3 & 3 & $39.0 \pm 9.9$ & $13.0 \pm 4.8$ \\
\hline Unknown & 2 & 8 & 10 & $31.5 \pm 12.4$ & $10.5 \pm 3.2$ \\
\hline TOTAL & 32 & 68 & 100 & $284.6 \pm 114.7$ & $94.9 \pm 34.8$ \\
\hline
\end{tabular}

The mean total heterotrophic bacteria count (THBC) showed that the highest count was within the age range $16-25$ years $\left(39.5 \pm 14.0 \times 10^{2}\right.$ $\mathrm{cfu} / \mathrm{mL}$ ), while the least count was in the age range $56-65$ years $\left(31.0 \pm 18.8 \times 10^{2} \mathrm{cfu} / \mathrm{mL}\right)$. The highest total coliform count (TCC) was obtained from the age range $16-25$ years $\left(13.2 \pm 5.7 \times 10^{2}\right.$ $\mathrm{cfu} / \mathrm{mL})$ ) while the least count $\left(10.3 \pm 2.8 \times 10^{2}\right.$ the highest antibiotics resistance was $38.3 \%$ to sulfamethoxazole/trimethoprim, while the least was $0.8 \%$ to ertapenem. Resistance of the isolates to chloramphenicol was $33.3 \%$, while it was 31.6\% (Aztreonam), 28.7\% (amoxicillin/clavulanate), 27.5\% (cefpodoxime), 21.2\% (cefotaxime), 18.7\% (ceftazidime), 18.3\% (gentamicin), and $15.8 \%$ (ciprofloxacin) (Table 3). 
Table 2: Prevalence of The Gram-negative Bacteria in the stool samples in Relation to HIV and AIDS patient's Age

\begin{tabular}{|c|c|c|c|c|c|c|c|c|c|}
\hline \multirow[b]{2}{*}{ Bacteria Isolates } & \multirow[b]{2}{*}{$16-25$} & \multirow[b]{2}{*}{$26-35$} & \multirow[b]{2}{*}{$36-45$} & \multicolumn{3}{|c|}{ Age Group (in year) } & \multirow[b]{2}{*}{$76-83$} & \multirow[b]{2}{*}{$\begin{array}{l}\text { No Age } \\
\text { Detail }\end{array}$} & \multirow[t]{2}{*}{ TOTAL (\%) } \\
\hline & & & & 46-55 & $56-65$ & $66-75$ & & & \\
\hline Escherichia coli & $14(14.0)$ & $9(9.0)$ & $11(11.0)$ & $12(12.0)$ & $15(15.0)$ & $16(16.0)$ & $17(17.0)$ & $6(6.0)$ & $100(41.6)$ \\
\hline Klebsiella pneumoniae & $4(12.9)$ & $1(3.0)$ & $2(6.1)$ & $3(9.1)$ & $5(15.2)$ & $6(18.2)$ & $9(27.3)$ & $3(9.1)$ & $33(13.8)$ \\
\hline Serratia marcescens & $4(14.8)$ & $1(3.7)$ & $2(7.4)$ & $3(11.1)$ & $4(14.8)$ & $5(18.5)$ & $6(22.2)$ & $2(7.4)$ & $27(11.3)$ \\
\hline Salmonella enteric & $3(15.0)$ & $0(0.0)$ & $1(5.0)$ & $2(10.0)$ & $3(15.0)$ & $4(20.0)$ & $5(25.0)$ & $2(10.0)$ & $20(8.3)$ \\
\hline Proteus vulgaris & $1(11.1)$ & $0(0.0)$ & $0(0.0)$ & $1(11.1)$ & $2(22.2)$ & $2(22.2)$ & $3(33.3)$ & $0(0.0)$ & $9(3.8)$ \\
\hline Proteus mirabilis & $1(7.7)$ & $0(0.0)$ & $0(0.0)$ & $1(7.7)$ & $2(15.4)$ & $3(23.1)$ & $5(38.5)$ & $1(7.7)$ & $13(5.4)$ \\
\hline Citrobacter freundii & $3(14.3)$ & $1(4.8)$ & $1(4.8)$ & $2(9.5)$ & $3(14.3)$ & $4(19.1)$ & $5(23.8)$ & $2(9.5)$ & $21(8.8)$ \\
\hline Enterobacter aerogenes & $1(5.9)$ & $0(0.0)$ & $0(0.0)$ & 2 (11.8) & $3(17.7)$ & $4(23.5)$ & 5 (29.4) & $2(11.8)$ & $17(7.1)$ \\
\hline TOTAL & $31(12.9)$ & $12(5.0)$ & $17(7.1)$ & $26(10.8)$ & 37 (15.4) & $44(18.3)$ & $55(22.9)$ & $18(7.5)$ & 240 \\
\hline
\end{tabular}

The overall prevalence of ESBL producers among the isolates in this study was $23.3 \%(56 / 240)$. It was observed that $23(41.0 \%)$ E. coli produced ESBL while, 9 (16.0\%), 6 (10.7), 5 (8.9\%), and 2 (3.5\%) Klebsiella pneumonia, Serratia marcescens, Salmonella enterica, and Citrobacter freundii, respectively also produced ESBL (Table 4).

Table 3: Susceptibility Profile of the Gram-negative Bacteria Isolated from the Stool Samples of the HIV and AIDS Patients in Ibadan

\begin{tabular}{lccc}
\hline Antibiotics & S & I & R \\
\hline SXT & $128(53.3)$ & $20(8.3)$ & $92(38.3)$ \\
CN & $195(81.2)$ & $16(6.6)$ & $44(18.3)$ \\
ETP & $236(98.3)$ & $2(0.8)$ & $2(0.8)$ \\
CPD & $151(62.9)$ & $23(9.5)$ & $66(27.5)$ \\
CAZ & $178(74.1)$ & $17(7.0)$ & $45(18.7)$ \\
AMC & $145(60.4)$ & $35(14.5)$ & $69(28.7)$ \\
CIP & $207(86.2)$ & $15(6.2)$ & $38(15.8)$ \\
C & $135(56.2)$ & $25(10.4)$ & $80(33.3)$ \\
CTX & $167(69.2)$ & $22(9.6)$ & $51(21.2)$ \\
ATM & $142(59.1)$ & $30(12.5)$ & $76(31.6)$ \\
\hline
\end{tabular}

SXT- Trimethoprim/Sulfamethoxazole; CN- Gentamicin; ETP- Ertapenem; CPD-Cefpodoxime; CAZ- Ceftazidime; AMCAmoxicillin/clavulanate; CIP-Ciprofloxacin; CChloramphenicol; CTX- Cefotaxime; ATM-Aztreonam R Resistance; I - Intermediate; S - Susceptibility

The occurrence of ESBL production in relation to the age range of the patients showed that isolates recovered from patients within the age range 7683 years produced the highest (26.8\%) ESBL, while it was $23.2 \%$ among the isolates within the age range 66-75 years. Among the isolates recovered from the age range $26-35$ and $36-45$ years, ESBL production was $3.6 \%$ and $5.4 \%$, respectively (Table 5).

Table 4: Prevalence of ESBL and Non-ESBL Producing Isolates

\begin{tabular}{lcc}
\hline \multicolumn{1}{c}{ Isolates } & $\begin{array}{c}\text { Number of } \\
\text { ESBL } \\
\text { Positive }\end{array}$ & $\begin{array}{c}\text { Number of } \\
\text { ESBL } \\
\text { Negative }\end{array}$ \\
\hline Escherichia coli & $23(41.1)$ & $77(41.8)$ \\
Klebsiella pneumonia & $9(16.0)$ & $24(13.0)$ \\
Serratia marcescens & $6(10.7)$ & $21(11.4)$ \\
Salmonella enterica & $5(8.9)$ & $15(8.1)$ \\
Proteus vulgaris & $3(5.4)$ & $6(3.3)$ \\
Proteus mirabilis & $5(8.9)$ & $8(4.3)$ \\
Citrobacter freundii & $2(3.5)$ & $19(10.3)$ \\
Enterobacter aerogenes & $3(5.3)$ & $14(7.6)$ \\
\hline & $\mathbf{5 6 ( 2 3 . 3 )}$ & $\mathbf{1 8 4 ( 7 6 . 3 )}$ \\
\hline
\end{tabular}

Comparison of the antibiotics resistant patterns of the ESBL and non-ESBL producing isolates showed that $80.3 \%$ and $25.5 \%$ of the ESBL producing isolates and non-ESBL producers were resistant to Trimethoprim/Sulfamethoxazole, respectively. 
Table 5: Prevalence of ESBL Producers in Relation to Age of the patients

\begin{tabular}{|c|c|c|c|c|c|c|c|c|c|}
\hline \multirow{2}{*}{ Bacteria Isolates } & \multicolumn{8}{|c|}{ Age Range } & \multirow[t]{2}{*}{$\begin{array}{c}\text { TOTAL } \\
(\%)\end{array}$} \\
\hline & $16-25$ & $26-35$ & $36-45$ & $46-55$ & $56-65$ & $66-75$ & $76-83$ & $\begin{array}{c}\text { No Age } \\
\text { Detail }\end{array}$ & \\
\hline Escherichia coli & $3(13.0)$ & $1(4.4)$ & $1(4.4)$ & $2(8.7)$ & $3(13.0)$ & $5(21.7)$ & $6(26.1)$ & $2(8.7)$ & $23(42.6)$ \\
\hline Klebsiella pneumonia & $1(11.1)$ & $0(0.0)$ & $1(11.1)$ & 1 (11.1) & $1(11.1)$ & $2(22.2)$ & $2(22.2)$ & $1(11.1)$ & $9(16.7)$ \\
\hline Serratia marcescens & $1(16.7)$ & $0(0.0)$ & $0(0.0)$ & $0(0.0)$ & $1(16.7)$ & $2(33.3)$ & $2(33.3)$ & $0(0.0)$ & $6(11.1)$ \\
\hline Salmonella enterica & $0(0.0)$ & $0(0.0)$ & $1(20.0)$ & $1(20.0)$ & $1(20.0)$ & $1(20.0)$ & $1(20.0)$ & $0(0.0)$ & $5(9.3)$ \\
\hline Proteus vulgaris & $1(33.3)$ & $0(0.0)$ & $0(0.0)$ & $0(0.0)$ & $0(0.0)$ & $0(0.0)$ & $1(33.3)$ & $1(0.0)$ & $3(5.6)$ \\
\hline Proteus mirabilis & $1(20.0)$ & $1(20.0)$ & $0(0.0)$ & $0(0.0)$ & $1(20.0)$ & $1(20.0)$ & $1(20.0)$ & $0(0.0)$ & $5(9.3)$ \\
\hline Citrobacter freundii & $0(0.0)$ & $0(0.0)$ & $0(0.0)$ & $0(0.0)$ & $0(0.0)$ & $1(50.0)$ & $1(50.0)$ & $0(0.0)$ & $2(3.7)$ \\
\hline Enterobacter aerogenes & $0(0.0)$ & $0(0.0)$ & $0(0.0)$ & $0(0.0)$ & $0(0.0)$ & $1(33.3)$ & $1(33.3)$ & $1(33.3)$ & $3(5.6)$ \\
\hline TOTAL & $\begin{array}{c}7 \\
(12.5)\end{array}$ & $2(3.6)$ & $3(5.4)$ & $4(7.1)$ & $\begin{array}{c}7 \\
(12.5)\end{array}$ & $13(23.2)$ & $15(26.8)$ & $5(8.9)$ & 56 \\
\hline
\end{tabular}

Furthermore, while $51.8 \%, 69.6 \%$ and $3.5 \%$ of the ESBL producing isolates showed resistance to Cefotaxime, Chloramphenicol and Ertapenem, resistant of the non-ESBL producing isolates to these respective antibiotics was $12.0 \%, 22.3 \%$ and $0 \%$.

Table 6: Comparative Antibiotic Resistant Pattern of ESBL and Non-ESBL Producing Isolates from HIV and AIDS Patients in Ibadan

\begin{tabular}{lclll}
\hline Antibiotics & Number & $\begin{array}{l}\text { ESBL } \\
\text { Resistant } \\
\text { (n = 56) }\end{array}$ & $\begin{array}{l}\text { Non-ESBL } \\
\text { Resistant } \\
\text { (n = 184) }\end{array}$ & $\begin{array}{l}\text { P- } \\
\text { value }\end{array}$ \\
\hline CTX & 51 & $29(51.8)$ & $22(12.0)$ & 0.000 \\
CAZ & 45 & $25(44.6)$ & $20(10.9)$ & 0.030 \\
CPD & 66 & $34(60.7)$ & $32(17.3)$ & 0.026 \\
ATM & 76 & $36(64.2)$ & $40(21.7)$ & 0.021 \\
CN & 44 & $19(33.9)$ & $25(13.6)$ & 0.954 \\
CIP & 38 & $19(33.9)$ & $19(10.3)$ & 0.152 \\
SXT & 92 & $45(80.3)$ & $47(25.5)$ & 0.001 \\
C & 80 & $39(69.6)$ & $41(22.3)$ & 0.005 \\
ETP & 2 & $2(3.5)$ & $0(0.0)$ & 0.087 \\
AMC & 69 & $34(60.7)$ & $35(19.0)$ & 0.012 \\
\hline
\end{tabular}

SXT- Trimethoprim/Sulfamethoxazole, CN- Gentamicin,ETPErtapenem,CPD-Cefpodoxime,CAZ- Ceftazidime, AMCAmoxicillin/clavulanate,CIP-Ciprofloxacin,CChloramphenicol,CTX- Cefotaxime, ATM-Aztreonam

The observation from the comparison of the ESBL producers and non-ESBL producers in this study showed that the difference was only statistically significant with Cefotaxime, Trimethoprim/Sulfamethoxazole and Chloramphenicol ( $p>0.005)$. Generally, the resistant of the non-ESBL producing isolates to all the tested antibiotics in this study were lower compared to the ESBL producers (Table 6).

The antibiotypes of the ESBL producing isolates in this study showed that of the 23 (41.1\%) E. coli that showed resistance to two or more antibiotics, eight (34.9\%) and six (26.1\%) were resistant to four and five antibiotics, respectively. While three $(33.3 \%)$ each of the $K$. pneumonia exhibited resistance to five and six antibiotics, respectively. Three (60.0\%) Citrobacter freundiishowed resistance to five antibiotics, while two (66.7\%) Enterobacter aerogenes exhibited resistance to five antibiotics. Generally, 22 (39.3\%), $14(25.0 \%)$ and $3(5.4 \%)$ of the 56 ESBL producing isolates showed resistance to a combination of five, six and seven antibiotics, respectively (Table 7).

\section{DISCUSSION}


Table 7: Antibiotype of Extended Spectrum Beta-Lactamase Producing isolates

\begin{tabular}{|c|c|c|c|c|c|c|c|c|}
\hline \multirow[t]{2}{*}{ Isolate } & \multirow{2}{*}{$\begin{array}{c}\text { Number of } \\
\text { isolate }\end{array}$} & \multicolumn{6}{|c|}{ Numbers of antibiotics } & \multirow[t]{2}{*}{ Total } \\
\hline & & 2 & 3 & 4 & 5 & 6 & 7 & \\
\hline E. coli & $23(41.1)$ & $1(4.4)$ & $1(4.4)$ & $6(26.1)$ & $8(34.9)$ & $6(26.1)$ & $1(4.4)$ & $23(41.1)$ \\
\hline Klebsiella pneumonia & $9(16.1)$ & - & - & $2(22.2)$ & $3(33.3)$ & $3(33.3)$ & $1(11.1)$ & $9(16.1)$ \\
\hline Serratiamarcescens & $3(5.4)$ & - & - & - & $1(33.3)$ & $3(100.0)$ & - & $5(5.4)$ \\
\hline Salmonella enterica & $5(8.9)$ & - & $1(20.0)$ & $1(20.0)$ & $3(60.0)$ & - & - & $5(8.9)$ \\
\hline Enterobacteraerogenes & $3(5.4)$ & $1(33.3)$ & - & - & $2(66.7)$ & - & - & $3(5.4)$ \\
\hline Citrobacterfreundii & $5(8.9)$ & - & $1(20.0)$ & - & $3(60.0)$ & - & $1(20.0)$ & $5(8.9)$ \\
\hline Proteus vulgaris & $3(5.4)$ & - & $1(33.3)$ & $1(33.3)$ & $1(33.3)$ & - & - & $3(5.4)$ \\
\hline Proteus mirabilis & $5(8.9)$ & - & $1(20.0)$ & $1(20.0)$ & $1(20.0)$ & $2(40.0)$ & - & $5(8.9)$ \\
\hline TOTAL & $56(100.0)$ & $2(3.6)$ & $4(7.1)$ & $11(19.6)$ & $22(39.3)$ & $14(25.0)$ & $3(5.4)$ & $56(100.0)$ \\
\hline
\end{tabular}

In this study, the prevalence and antibiotics resistance patterns of the ESBL producing Gram negative bacteria isolated from the stool samples of HIV and AIDS patients in two study locationsin Ibadan, Nigeria was evaluated. The total heterotrophic bacteria and coliform counts obtained from the study samples were comparatively higher in the lower age range and among the elderly. This finding is also in agreement with the report of a study on intestinal bacterial population where the total Enterobacteria count was higher among children and elderly compared to the adults [22].

The isolation of one or more enteric Gramnegative bacteria from all the stool samples of the HIV and AIDS patients in this study is in concordance with the $97.0 \%$ reported from a similar study in Cameroon [23]. Similarly, isolation of E. coli, $K$. pneumoniae, Salmonella enterica and Enterobacter aerogenes is in accordance with previous studies where these bacteria were also isolated [11, 23, 24]. Some of these bacteria are commonly associated with both intestinal and extra-intestinal opportunistic and non-opportunistic infections among people living with HIV and AIDS. The observation from this present study that revealed $E$. coli having the highest occurrence rate agrees with the report from similar studies on the prevalence of Gramnegative bacteria associated with HIV and AIDS infected individuals in Benin city, Edo State, Nigeria [12], Zimbabwe [7], Cameroon [25] and Nepal [26]. The reason for this observation might be because $E$. coli is traditionally a normal flora of the gut.

Although, the occurrence of bacterial isolates in samples from the female participants in this study is higher compared to the male counterparts, the difference is not statistically significant ( $p>0.05$ ). This observation is however not in agreement with statistically higher prevalence previously reported for isolates recovered from sputum samples of HIVand AIDS male patients compared to their female counterparts [27]. The variation might be due to differences in the study samples, type of isolates and underline health condition considered in the latter study. However, the observation from this study is in agreement with the recovery of more Enterobacteriaceae in female compared to the male patients on several clinical samples in Ethiopia [28].

Furthermore, the low resistance $(0.8 \%)$ of the isolates in this study to ertapenem, as well as $15.8 \%, 18.3 \%$ and $18.7 \%$ resistance of the isolates to ciprofloxacin, gentamicin and ceftazidime, respectively is in agreement with a previous report onenteric pathogens isolated from stool samples of HIV-infected individuals 
attending Anti-retroviral Clinic in Hawassa University Hospital, Ethiopia, where a low resistance patterns were observed to nalidixic acid, gentamicin, norfloxacin, ceftriaxone and ciprofloxacin [29]. Similarly, a low resistance patterns similar to the observation from this study was also reported among the Enterobacteriaceae isolated from HIV-infected patients in Kinshasa to gentamicin [30]. In addition, the $38.3 \%, 14.5 \%$ and $15.8 \%$ resistance of the isolates in the present study to trimethoprim/Sulfamethoxazole,

amoxicillin/clavulanate and ciprofloxacin, respectively contradicts the previously reported $25.0 \%, 66.0 \%$ and $66.7 \%$ resistance to the respective antibiotics from a study carried out on similar isolates from HIV and AIDS patients in Bugando Medical Centre, Mwanza, Tanzania [31].The reason for the noticed differences may be as a result of the study samples. While the present study was on stool samples, the later study was on urine and pus samples.

Generally, global increase in resistance to antibiotics has been attributed to frequent, inappropriate and unregulated uses. The observed resistance to trimethoprim/sulfamethoxazole and chloramphenicol in this study can be attributed to the fact that the drugs are commonly used for routine empirical treatment, as prophylactic before and after surgery and also in cases of selfmedication by HIV patients [29].

The ESBL-producers (23.3\%) in this study is higher than the $13.7 \%$ reported from a study on HIV infected children in Zimbabwe [7]. This observation is however lower compared to the $64.2 \%, 44.5 \%$ and $34.3 \%$ reported previously from isolates recovered from faecal samples of children in Peru, community and hospital setting in Chad and turkish community $[8,9,11]$. The observed difference could be due to the study population. While the present study focused on
HIV and AIDS patients, the latter studies were on out patients and healthy volunteers.

The observation from the present study that showed E. coli being the most prevalent among the isolates that produced ESBL is not in agreement with the report of another study in Ethiopia from which E. coli was the least producers of ESBL among the studied Enterobacteriaceae isolates from clinical samples [28]. The reason for the differences might be due to the differences in the nature of the study samples. While this study was on isolates from the stool samples of HIV and AIDS patients, the latter study was on isolates collected from different laboratories which could has been isolated from several clinical samples. Similarly, the prevalence (41.1\%) of ESBL producing E. coli observed in this study is higher than the $35.0 \%$ reported from a study from another Tertiary Hospital in Enugu, a city in the Eastern part of the country on different clinical samples including urine, blood, wound swabs, pleural and peritoneal aspirate [32]. However, the prevalence of ESBL producing E. coli in this study is comparably similar to the $44.8 \%$ reported in a study carried out in a Tertiary Health facility in Benin City of Southern part of the country on urine and wound samples [33].

Moreover, production of ESBL in other Enterobacteriaceae in the present study including species of Klebsiella, proteus, Enterobacter and Citrobacter were generally lower compared to the latter study. The noticed disparity could be as a result of the differences in the study samples. While this study was on stool samples of HIV and AIDS patients, the latter study was on urine and wound samples. Furthermore, in Libya, the prevalence of $48.1 \%$ that was reported among the $E$. coli isolated from HIV and non-HIV patients [34]is a bit higher from the observed prevalence in this study. The little difference might be due to the study subjects. Comparing the prevalence of 
ESBL production in this study with the report of another study in Tanzania [35], it was higher in the isolates from this study except for Salmonella and Serratia species that the prevalence was lower.

Generally, the observation from this study that showed ESBL producing isolates exhibiting higher rate of resistance to the tested antibiotics and ertapenem being the most effective with the lowest level of resistance is in line with the report of another study in southern Nigeria with a similar observation [33]. Similarly, that the ESBL producing isolates exhibited higher resistance to trimethoprim/sulfamethoxazole and ciprofloxacin is also similar to the report from a study on bacterial isolates among patients with secondary peritonitis at Bugando Medical Centre, Mwanza, Tanzania [35].

\section{CONCLUSION}

The high rate of ESBL producing and multidrug resistant Enterobacteriaceae in faecal samples of the HIV and AIDS patients in this study indicates that people living with HIV and AIDS might be reservoir of multidrug resistant bacteria. This therefore demand serious attention and continuous monitoring of ESBL producing Gramnegative bacteria in immunocompromised individuals and guide their proper use of antimicrobials.

\section{ACKNOWLEDGEMENTS}

The authors acknowledge the support of the medical staff of Anti-retroviral (ARV) clinic of the APIN-PEPFAR, of the two healthcare facilities for their assistance in counselling the patients and in sample collection. We also appreciate the cooperation of all participants for the success of this study.

\section{REFERENCES:}

1. Pitout JD, Nordmann P, Laupland KB, Poirel L. Emergence of Enterobacteriaceae producing extendedspectrum $\beta$-lactamases (ESBLs) in the community. J Antimicrob Chemother. 2005;56: 52-90.

2. Bush K, Jacoby GA. An updated functional classification of beta-lactamases. J Antimicrob agents chemother 2010; 37: 851- 858.

3. Gales AC, Jones RN, Gordon KA, Sader HS, Wilke WW, Beach ML, Pfaller MA, Doern GV. Activity and spectrum of 22 antimicrobial agents tested against urinary tract infection pathogens in hospitalized patients in Latin America. J Antimicrob Chemother 2000; 45: 295-303.

4. Bradford PA. Extended-spectrum beta-lactamases in the $21^{\text {st }}$ century characterization, epidemiology and detection of this important resistance threat. Clin Microbiol Rev 2001; 14: 933-995

5. Obeng-Nkrumah N, Twum-Danso K, Krogfelt KA, Newman MJ. High levels of extended-spectrum betalactamases in a major teaching hospital in Ghana: the need for regular monitoring and evaluation of antibiotic resistance. Am J Trop Med Hyg, 2013; 89(5), 960-964.

6. Shaikh S, Fatima J, Shakil S, Rizvi SM, Kamal MA. Antibiotic resistance and extended spectrum betalactamases: Types, epidemiology and treatment. Saudi J Biol Sci 2015; 22(1), 90-101.

7. Wilmore S, Kranzer K, Williams A, Makamure B, Nhidza AF, Mayini J, Bandason T, Metcalfe J, Nicol MP, Balakrishnan I, Ellington MJ, Woodford N, Hopkins S, McHugh TD, Ferrand RA. Carriage of extendedspectrum beta-lactamase-producing Enterobacteriaceae in HIV-infected children in Zimbabwe. J Med Microbiol 2017; 66(5), 609-615.

8. OucharMahamat 0 , Tidjani A, Lounnas $M$, Hide $M$, Benavides J, Somasse C, Ouedraogo AS, Sanou S, Carrière $\mathrm{C}$, Bañuls $\mathrm{AL}$, Jean-Pierre $\mathrm{H}$, Dumont $\mathrm{Y}$, Godreuil S. Fecal carriage of extended-spectrum $\beta$ lactamase-producing Enterobacteriaceae in hospital and community settings in Chad. Antimicrob Resist Infect Contrl 2019; 8, 169.

9. Hazirolan G, Mumcuoglu I, Altan G, Özmen BB, Aksu N, Karahan ZC. Fecal carriage of extended-spectrum betalactamase and Ampcbeta-lactamase-producing enterobacteriaceae in a turkish community. Niger J Clin Pract. 2018; 21:81-6.

10. Luvsansharav UO, Hirai I, Niki M, Nakata A, Yoshinaga A, Moriyama T, Yamamoto Y. Prevalence of fecal carriage of $\quad$ extended-spectrum $\quad \beta$-lactamase-producing Enterobacteriaceae among healthy adult people in Japan. J Infect Chemother2011; 17(5), 722-725.

11. Aliaga FC, Andrade CS, Escalante EG. Enterobacteriasproductoras de betalactamasas de espectroextendidoenmuestrasfecalesen el InstitutoNacional de Saluddel Niño, Perú Extended- 
spectrum beta-lactamase (esbl)-producing enterobacteriaceae in fecal samples at the National Institute of Child Health, Peru. Revistaperuana de Med Experimental Saludpublica, 2015; 32(1), 26-32.

12. OsazuwaF, Osazuwa EO, Imade P,Dirisu J, Omoregie, R, Okuonghae $P$,Aberare 0 . Occurrence of extended spectrum producing gram negative bacteria in HIV/AIDS infected patients with urinary and gastrointestinal tract infections in Benin metropolis. Res J Pharma Biolog Chem Sci. 2011; 2(2): 230-234

13. Tham J, Odenholt I, Walder M, Melander E, Odenholt I. Extended-spectrum beta-lactamase-producing Escherichia coli in patients with travellers'diarrhoea. Scand J Infect Dis, 2010; 42: 275-280.

14. Warren R, Butler VN, O'Neill K, Taylor J, Ensor V, Harvey P. Imported chicken meat as a potential source of quinolone-resistant Escherichia coli producing extended-spectrum $\beta$-lactamases in the UK. J Antimicrob Chemother 2008; 61(3), 504-508.

15. Bloomberg B, Jureen R, Manji KP, Tamim BS, Mwakagile DSM, Urassa WK, Fataki M, Msangi V. High rate of fatal cases of pediatric septicemia causedby Gram-negative bacteria with extended-spectrum beta-lactamases in Dar es Salaam, Tanzania. J Clin Microbiol 2005; 43:745749

16. Fam NS, Defasque S, Bert F, Leflon-Guibout V, El-Ray A, El-Ghannam M, Attia ME, Omar M, Desouki DG, Valla D, Nicolas-Chanoine MH. Faecal carriage of extendedspectrum $\beta$-lactamase (ESBL)-producing enterobacteria in liver disease patients from two hospitals in Egypt and France: a comparative epidemiological study. Epidemiol Infect 2015; 143(6), 1247-1255.

17. Jallad MA, Naoufal R, Irani J, Azar E. Extended spectrum beta-lactamase carriage state among elderly nursing home residents in Beirut. ScientWorld J. 2015; 2015: 17

18. Doi Y, Iovleva A, Bonomo RA. The ecology of extendedspectrum $\beta$-lactamases (ESBLs) in the developed world. J Trav Med 2017; 24: S44-S51.

19. Adenaike O, Olunitola OS, Ameh JB Whong CMZ. Incidence of Extended Spectrum Beta-lactamase, producing Bacteria and Multidrug Resistance Strains from Proceed Mean Suya Sold in a University Community. Inter J Engineer Sci 2013; 2:2319-1805

20. Tamuno I, Mohammed S. Self-medication with antibiotics among students of a Nigerian Tertiary institution. J Basic Appl Sci Res2011; 1: 1319-1326

21. Clinical and Laboratory Standards Institute (CLSI). Performance Standards for Antimicrobial Susceptibility Testing: Twenty-sixth Information Supplement CLSI document M100-S26. Wayne, P. A. 2016. 38:1-251

22. Hopkins MJ, Sharp R, Macfarlane GT. Age and diseases related changes in intestinal bacterial population assessed by cell culture, 16S rRNA abundance, and community cellular fatty acid profiles. J Gut Microbiol. 2001; 48: 198-205

23. Ngalani OJT, Mbaveng,. T, Marbou WJT, Ngai RY,Kuete V. Antibiotic Resistance of Enteric Bacteria in HIV-Infected Patients at the Banka Ad-Lucem Hospital, West Region of Cameroon. Canadian Journal of Infectious Diseases and Medical Microbiology 2019; 2: 2019

24. Obi CL, Ramalivhana J, Momba MNB, Onabolu B, Igumbor JO, Lukoto M, Mulaudzi TB, Bessong PO, Jansen van Rensburg EL, Green E, Ndou S. Antibiotic resistance profiles and relatedness of enteric bacterial pathogens isolated from HIV/AIDS patients with and without diarrhoea and their household drinking water in rural communities in Limpopo Province South Africa. Afri J Biotechnolo 2007; 6 (8): 1035-1047

25. Marbou W, Kuete V. Bacterial resistance and immunological profiles in HIV-infected and non-infected patients at Mbouda AD LUCEM Hospital in Cameroon. J infect Pub hlth, 2017; 10(3), 269-276.

26. HosuruSubramanya S, Bairy I, Nayak N, Padukone S, Sathian B, Gokhale S. Low rate of gut colonization by extended-spectrum $\quad \beta$-lactamase producing Enterobacteriaceae in HIV infected persons as compared to healthy individuals in Nepal. PLoS ONE 2019; 14(2): e0212042.

27. Ojo-Bola O, Oluyege A0. Antibiotics Resistance of Bacteria Associated with Pneumonia in HIV/AIDS Patients in Nigeria. Am J Infect Dis Microbiol.2014; 2 (6): 138-144

28. Teklu DS, Abebe NA, Legese MH, Bedada TL, Woldemariam HK, Tullu KD. Extended-spectrum betalactamase production and multi-drug resistance among Enterobacteriaceae isolated in Addis Ababa, Ethiopia. J Antimicrob Resist Infect Ctrl. 2019; 1-12

29. Kebede A, Aragie S, Shimelis T. The common enteric bacterial pathogens and their antimicrobial susceptibility pattern among HIV-infected individuals attending the antiretroviral therapy clinic of Hawassa university hospital, southern Ethiopia. Antimicrob Resist Infect Ctrll, 2017; 6, 128.

30. Iyamba JM, Wambale JM, Takaisi-Kikuni NZ. Antimicrobial susceptibility patterns of enterobacteriaceae isolated from HIV-infected patients in Kinshasa. Pan Afri Med J. 2014; 17, 179.

31. Karol J, Marwa 1, Martha F, Mushi Eveline K, Paul E, Alele JK, Mariam MM. Resistance to Cotrimoxazole and Other Antimicrobials among Isolates from HIV/AIDS and Non-HIV/AIDS Patients at Bugando Medical Centre, Mwanza, Tanzania. Clin Pharmacol J. 2015; 1-8

32. Nwafia IN, Ohanu ME, Ebede SO, Ozumba UC. Molecular detection and antibiotic resistance pattern of extended-spectrum beta-lactamase producing 
Escherichia coli in a Tertiary Hospital in Enugu, Nigeria. Ann Clin Microbiol Antimicrob2019; 18:41, 1-7

33. Ogefere HO, Aigbiemwen PA, Omoregie R. ExtendedSpectrum Beta-Lactamase (ESBL)-Producing Gramnegative Isolates from Urine and Wound Specimens in a Tertiary Health Facility in Southern Nigeria. Trop J Pharmaceut Res. 2015; 14(6): 1089-1094

34. Buzayan MM, El-Garbulli FR. Detection of ESBL and AmpC -lactamasesproducing in uropathogenEscherichia coli isolates at Benghazi Center of Infectious Diseases and Immunity. Int J Current Microbiol Appl Sci 2014; 3: 145-153

35. Seni J, Sweya E, Mabewa A, Mshana SE, Gilyoma JM. Comparison of antimicrobial resistancepatterns of ESBL and non ESBL bacterialisolates among patients with secondaryperitonitis at Bugando Medical Centre,Mwanza-Tanzania BMC Emerg Med 2016; 16:41 